\title{
Los medios técnicos de defensa
}

Marco Antonio Ulloa Reyna*

http://dx.doi.org/10.21503/lex.v9i8.408

* Docente Universitario del Curso de Derecho Procesal y Derecho Penal en la Universidad Alas Peruanas e Inca Garcilaso de la Vega , Maestro en Derecho en Ciencias Penales, doctorando en Derecho, posgrado en administración de Justicia, perteneciente a la Quinta Promoción del curso de formación para Magistrados de la Academia de la Magistratura, con estudios en la Academia de la Magistratura, ex Magistrado de la Corte Superior de Justicia de Lima, ex director de Defensa Gremial del Colegio de Abogados de Lima, conferencista, panelista, miembro de Comisiones de Estudio del Colegio de Abogados, articulista y autor de libros. 



\section{Los medios técnicos de defensa}

Conforme lo indica su nombre, los medios técnicos de defensa son aquellos medios que solo el imputado puede presentar o que pueden ser deducidos de oficio por el juez. La norma procesal señala el trámite que tiene cada uno de los medios técnicos de defensa, llamados así por que debe ser un profesional del derecho quien debe sustentarlos, por cuanto el imputado no es una persona entendida.

Los medios técnicos de defensa que tiene el imputado para oponerlos a la persecución del delito, de conformidad con lo dispuesto por los artículos $4^{\circ}$ y $5^{\circ}$ del Código de Procedimientos Penales, son:

- Las cuestiones previas

- Las cuestiones prejudiciales

- Las excepciones

\section{La cuestión previa}

La Cuestión Previa es un medio de defensa técnico que se opone a la acción cuando falta algún requisito de procedibilidad, por lo tanto, conforme lo expone Marco de la Cruz Espejo en su libro Cuestión Previa y otros mecanismos de defensa, en referencia al citado medio, el requisito de procedibilidad nada tiene que ver con la verdad o la falsedad de la imputación ni con los elementos de la tipicidad. Se trata simplemente de condiciones que, sin referirse al delito mismo, deben cumplirse porque así lo dispone la ley penal. Esta pone en conocimiento la ausencia de un requisito de procedibilidad. De ser así, la Cuestión Previa será considerada fundada al existir un obstáculo a la acción penal.

Son requisitos de procedibilidad todas aquellas causas que condicionan el ejercicio de la acción penal y sin cuya presencia no es posible promoverla. Por ello, la Cuestión Previa constituye un medio, un obstáculo al ejercicio de la acción penal que reclama que se cumplan determinados actos señalados por ella, los mismos que son exigidos por ley. 
En dichos casos, en que no son suficientes los requisitos generales para la apertura de instrucción, tanto el Fiscal Provincial -al promover la acción penal-, como el juez -al dictar el auto de apertura de instrucción- deben tener en cuenta el cumplimiento de esas condiciones. De no haber sido observadas, procede a deducir la Cuestión Previa, a fin de subsanar el requisito omitido, que es un mecanismo o medio de defensa que permite reponer al estado anterior. Otra instrucción sobre el mismo hecho no procederá hasta que se cumplan los supuestos condicionantes.

La Cuestión Previa se constituye así en un medio de subsanación del Auto de Apertura de Instrucción en el que se obvió la constatación del cumplimiento de los requisitos de procedibilidad. Por ello, la ley procesal penal prevé que esta Cuestión Previa pueda ser deducida de oficio.

Son requisitos de procedibilidad, por ejemplo, el requerimiento, al obligado, para el pago de pensiones alimenticias bajo apercibimiento de ser denunciado penalmente y la notificación hecha en su domicilio real. El informe técnico que deberá emitir la Oficina de Derechos de Autor del Indecopi para promover acción penal por delitos contra los derechos de autor previstos en los artículos $216^{\circ}$ al $221^{\circ}$ del Código Penal. También es un requisito de procedibilidad, en los delitos de libramientos indebidos, que el título valor tenga el sello de no pagado estampado por el banco y que se haya formulado el requerimiento de pago. También en los delitos de quiebra fraudulenta se requiere una serie de requisitos, que señala la ley extrapenal, sin los cuales el Fiscal Provincial no podrá dar inicio al ejercicio de la acción penal pública.

En los casos de Antejuicio Constitucional al que tienen derecho los altos dignatarios del país, se trata de un procedimiento especial que debe cumplirse y la norma procesal debe ser respetuosa de tal procedimiento, siendo el trámite el señalado en los artículos 99 y 100 de nuestra Carta Magna. El derecho a antejuicio es una prerrogativa prevista a favor del Presidente de la República, los congresistas, los ministros de Estado, los miembros del Tribunal Constitucional, así como los del Consejo de la Magistratura, los vocales supremos, los fiscales supremos, el Defensor del Pueblo y el Contralor General de la República, planteándose desde que ejercen el cargo y hasta cinco años después que hayan cesado en éste.

Asimismo, en los casos de delito de falso testimonio, es necesario que exista un proceso concluido en el que el magistrado haya valorado el testimonio en el estadio de la sentencia, por lo que resulta prematuro que una de las partes afectadas con el testimonio denuncie el hecho y que tal denuncia tenga aceptación por parte del Ministerio Público. El afectado podría plantear el presente medio técnico de defensa por faltarle tal requisito de procedebilidad. 
También existe una serie de delitos, como los delitos contra los derechos de autor y conexos, los delitos tributarios, los delitos contra el medio ambiente, y los comprendidos en la ley de representación de la competencia desleal, en los que es necesario la opinión de una entidad como Indecopi, Sunat, o entidades sectoriales competentes, sin las cuales no cabe iniciar la acción penal.

En diversos casos - como el expediente 6806-97 Lima, sobre un proceso por omisión de asistencia familiar con sentencia de Primera Instancia-, la jurisprudencia nacional declaró nula la sentencia por estimar que no se había acreditado fehacientemente, pues era necesario que el procesado cumpla con su obligación bajo apercibimiento de ser denunciado. Actuando de oficio en dicho caso, el órgano jurisdiccional declaró fundada la Cuestión Previa. Igualmente, en el expediente 2103-97 Lima, la sala penal declaró fundada la Cuestión Previa, deducida a favor del imputado, por estimar que no existía, en el título valor o en otro documento del banco, en forma expresa la constancia de que el cheque carecía de falta de fondos o la inexistencia de la cuenta corriente con la que fue girado el cheque.

La Cuestión Previa puede ser deducida por el encausado o por el Ministerio Público o puede ser declarada de oficio en cualquier estado de la causa. Una vez deducida, no requiere de tramitación en cuaderno separado, ya que la decisión judicial es inmediata y se limita a analizar si se ha cumplido o no con los requisitos de procedibilidad.

Sin embargo, muchos órganos jurisdiccionales, en exceso de formalismo, abren la incidencia a prueba conforme lo establece el artículo 90 del Código de Procedimientos Penales. Este criterio, que incluso puede ser invocado por algunos autores, suele ser elegido por el titular del ejercicio de la acción penal pública. Desde mi punto de vista, no comparto el criterio de estos autores en cuanto a que dicho medio de defensa puede ser presentado incluso por la parte civil. En este sentido, el único perjudicado con su ejercicio sería la propia persona que interpone el medio de defensa, puesto que si anula todo lo actuado, solo podrá volver a denunciar luego de subsanar el requisito previo.

\section{Cuestión prejudicial}

Según el artículo $4^{\circ}$ del Código de Procedimientos Penales, el carácter delictuoso del hecho imputado procede cuando deba establecerse en otra vía. En consecuencia, se refiere a todo problema de naturaleza extra penal que surge en el desarrollo del proceso y que requiere un esclarecimiento por otra vía, cuyo resultado es necesario para resolver cualquier cuestión vinculada con ella, tal como es el delito investigado. Las cuestiones prejudiciales que reclaman una decisión previa constituyen así un obstáculo para la prosecución del proceso penal. 
Generalmente, las cuestiones prejudiciales tienen carácter civil o administrativo, aunque pueden tener otro carácter, según la causa.

En estos casos, el procesado reconoce la existencia del hecho que se le incrimina, pero sostiene que el mismo no tiene contenido penal. Así, por ejemplo, cuando se le denuncia por bigamia y admite que efectivamente ha contraído nuevo matrimonio, pero sostiene que el anterior matrimonio es nulo y que existe un proceso judicial para conseguir tal objetivo. De igual manera, una persona procesada por estafa reconoce el hecho que se le incrimina, pero niega que sea delito sosteniendo que existe un incumplimiento de contrato.

Si bien es cierto que establece el medio de defensa técnico, nuestro ordenamiento procesal no señala cuál es el procedimiento que deba seguirse si se declara fundado el medio de defensa técnico. Esto es así porque, de lo contrario, la suspensión del proceso penal, sin tener un correlato en la vía extrapenal, carece de eficacia en la solución del conflicto.

La cuestión prejudicial se encuentra regulada en el artículo $4^{\circ}$ del Código de Procedimientos Penales que, a la letra, dice: "Las cuestiones prejudiciales proceden cuando debe establecerse en otra vía el carácter delictuoso el hecho imputado". Procede deducirla en cualquier momento de la etapa investigadora, luego de haber sido prestada la declaración instructiva y antes de remitirse la instrucción al Fiscal Provincial para dictamen. De ser planteada posteriormente, esta cuestión prejudicial será considerada como elemento de defensa.

Una vez formulada la cuestión prejudicial, el juez ordenará la formación de un cuaderno aparte, ya que el proceso debe continuar su trámite. La cuestión prejudicial se tramita como un incidente y por tanto el término probatorio es de 8 días, según se dispone en el artículo $90^{\circ}$ del Código de Procedimientos Penales. Requiere del pronunciamiento del fiscal para que el juez de la causa resuelva a las cuestiones prejudiciales, además el representante del Ministerio Público puede interponer recursos impugnatorios contra las decisiones judiciales en esta materia. El juez puede declarar fundada o infundada la cuestión prejudicial. De ser fundada, se ordenará la suspensión del proceso a la espera de la resolución judicial en la vía extrapenal, de ser infundada se continúa el trámite de la investigación.

Es conveniente señalar que de existir varios procesados en una misma causa por el mismo delito, la cuestión prejudicial que uno de ellos deduzca tendrá como consecuencia la suspensión del proceso para todos. De existir varios encausados por diferentes delitos, la cuestión previa referida a uno de los delitos que es declarada fundada trae consigo la suspensión del proceso al o a los encausados por ese delito, continuándose la tramitación del proceso para los demás.

La jurisprudencia nacional, en los casos sobre cuestiones pre judiciales, ha señalado, como precedente en el expediente 2138 -97, que las cuestiones prejudiciales, según lo ha señalado 
el artículo $4^{\circ}$ del Código de Procedimientos Penales, solo pueden deducirse luego de haberse prestado la instructiva y hasta que remita la instrucción al Fiscal Provincial para su dictamen final, por lo que, en estos casos, debe declararse improcedente el medio de defensa deducido.

\section{Excepciones}

En general, las excepciones como medios de defensa del imputado tienen por fin exponer la improcedencia de la acción penal y terminar con la pretensión punitiva del Estado. En nuestro ordenamiento, la excepción es un derecho que se contrapone a la acción penal, por el cual se invocan razones que extinguen la acción, la impiden, la modifican o regularizan su trámite. Nuestro ordenamiento procesal prevé cinco excepciones, las mismas que se encuentran establecidas en el artículo $5^{\circ}$ del Código de Procedimientos Penales y son las siguientes:

- Excepción de Cosa Juzgada

- Excepción de Prescripción

- Excepción de Naturaleza de Acción

- Excepción de Naturaleza de Juicio

- Excepción de Amnistía.

\subsection{La excepción de Cosa Juzgada}

Debemos empezar sosteniendo que la Cosa Juzgada es el efecto jurídico de la conclusión de un proceso por una resolución judicial firme. Debiendo entender por "firme", la inexistencia, contra ella, de recurso alguno ordinario o extraordinario (salvo la revisión y la rehabilitación), o la existencia de una modificatoria de la ley. Así, podemos decir que una resolución es firme cuando sea invariable por el tribunal que lo dictó e inimpugnable por las partes.

Es importante resaltar que este efecto jurídico trae consigo que un proceso termine respecto de una determinada persona. Así, la Cosa Juzgada es el efecto de un proceso terminado, no de un acto procesal como es la Sentencia. Sólo así podemos hablar de la procedencia del recurso de revisión.

Es a partir de aquí que podemos referimos a la excepción de Cosa Juzgada. Para que esta excepción se declare fundada por el órgano jurisdiccional, será necesario que cumpla ciertos requisitos propios de esta institución. El fundamento de esta excepción se encuentra en el principio del non bis in idem "no dos veces por la misma causa", consagrada en la Constitución Política del Perú en su artículo $139^{\circ}$ inc. 13. 
Todo ordenamiento civilizado debe permitir al condenado poder agotar, por medio de la vía recursal, la instancia. De esta manera, luego de haberse llevado a cabo un proceso regular, el imputado puede ejercer su derecho de defensa presentando todos los recursos que la ley le franquea a fin de hacer valer sus derechos, reconocidos tanto constitucionalmente, como en las normas procesales vigentes. Por otro lado, lo que de ninguna manera puede permitirse es atentar contra la Cosa Juzgada.

El maestro Domingo García Rada señala que la Cosa Juzgada funciona cuando se presenta la existencia de una condena anterior en la que el delito y la personas del encausado son idénticos a los que fueron objeto de instrucción posterior.

Por su parte, Marco de la Cruz Espejo indica sobre el tema que existen dos circunstancias que posibilitan que una sentencia inimpugnable, inmutable, coercible, pueda ser cambiada cuando se produzca una modificación de la ley penal, de manera que el recurso de revisión constituye un proceso extraordinario.

Cesar San Martin Castro señala, sobre la Cosa Juzgada, que toda resolución que pone fin a un proceso penal produce Cosa Juzgada. Cita como ejemplos los sobreseimientos, los autos que amparan las excepciones, excepto la de naturaleza de juicio. Nuestra jurisprudencia, a través de la Corte Suprema, incluye los autos que cortan la secuela de juicio (procesos en los que por error se ha procesado a menores de edad).

Existen algunos requisitos para declarar una Cosa Juzgada. En primer lugar, es necesaria la Identidad de Hecho. Esto significa que ambos procesos, en aquel en el cual se deduce la excepción y en aquel en se funda la excepción, deben estar referidos al mismo hecho, condición necesaria para establecer que el proceso no debe continuar, puesto que ya se ha sufrido un proceso por ese mismo hecho.

Es necesario no confundir la Identidad de Hecho con la tipificación que pueda dar el juzgador al abrir instrucción, lo cual puede variar por diversas razones: cambio de nomen iuris o por otra calificación judicial. Esta identidad debe buscarse en los fundamentos de hecho, tanto del auto apertorio como de la resolución judicial firme en que uno se ampara.

$\mathrm{Al}$ tratarse de un solo acto, la comprobación de la identidad no ofrece mayores problemas como cuando se trata de delitos de concurrencia real. Por lo que se exigirá que la resolución judicial contenga en sus fundamentos la totalidad de los hechos relacionados con la comisión delictuosa.

En segundo lugar es necesaria la Identidad del Sujeto. Este elemento está referido al requisito necesario de encontrarnos ante la misma persona, sujeto de la resolución judicial firme. Con 
ello, no se quiere decir que sea suficiente la comprobación de la igualdad de nombres, sino que hay que tener la certeza de que se trate de la misma persona, por las generales de ley que obren en el primer expediente, así como en el proceso en el cual se deduce la excepción.

La persona del procesado debe ser la misma persona física que, en una anterior ocasión, fue materia de sentencia condenatoria o absolutoria, resolución definitiva de sobreseimiento, u otra forma de extinción o medio de defensa técnico que produzca los efectos de la cosa juzgada.

En tercer lugar, es necesaria una Resolución Definitiva que concluya con el carácter irreversible del proceso penal en la que expide dicha resolución.

Entre algunos casos de Cosa Juzgada cabe destacar aquellos que pueden darse cuando existe una relación entre la sentencia civil y la sentencia penal. Así, de la Cruz Espejo sostiene que ha quedado claramente establecido que la sentencia pronunciada en la vía civil constituye un obstáculo a la acción penal respecto del hecho declarado lícito en dicha sentencia. De igual manera, la Cosa Juzgada de índole penal impide cualquier otra acción que pueda derivarse del hecho materia de juzgamiento. El artículo 79 del Código Penal establece que se extingue la acción penal si, a partir de la sentencia ejecutoriada dictada en la jurisdicción civil, el hecho imputado como delito es lícito.

En los delitos de Omisión de Asistencia Familiar, debe tenerse en cuenta que la suma de dinero reclamada por un periodo de tiempo no puede ser nuevamente materia de otra denuncia, por cuanto constituye Cosa Juzgada; sin embargo, esto no se aplica a las nuevas obligaciones impagas.

En lo relacionado a la Cosa Juzgada y a la modificación de la ley penal, el segundo párrafo del artículo $6^{\circ}$ del Código Penal establece que "si durante la ejecución de la sanción se dictare una ley más favorable al condenado, el juez sustituirá la sanción impuesta por la que corresponda conforme a la nueva ley".

\subsection{La excepción de Prescripción}

Uno de los requisitos para la apertura de instrucción es que la acción penal no haya prescrito. Especialmente, en el caso de haberse iniciado, la ley prevé la procedencia de la excepción de Prescripción que protege el derecho que tiene una persona a que el proceso penal no continúe por haber prescrito la acción penal en su contra. Los plazos de prescripción están establecidos en los artículos $80^{\circ}$ y $83^{\circ}$ del Código Penal vigente.

Bustos Ramírez sostiene que "pasado un determinado tiempo, se estima innecesaria la 
prosecución de una acción y la imposición de una pena solo por razones de tipo preventivo general o especial también en virtud del concepto mismo de la necesidad de la pena".

Entre los tipos de prescripción, tenemos la Prescripción Ordinaria y la Prescripción Extraordinaria. La Prescripción Ordinaria se refiere a que el tiempo de prescripción de la acción penal será igual al máximo de la pena fijada por la ley para el delito. Por ejemplo, Juan Pérez es denunciado en enero del 2005 por su vecino por el delito de usurpación cometido el 15 de julio del 2000. El delito antes citado tiene en nuestro Código Penal una pena máxima de tres años.

Teniendo en cuenta que tal ilícito penal es un delito de comisión instantánea, aunque tenga efectos permanentes, será de aplicación el artículo $82^{\circ}$ del Código Penal. Es decir, se empieza a computar el plazo de prescripción desde el 15 de julio del 2000; luego, a la fecha de la interposición de la denuncia, habrían transcurrido más de tres años, por lo cual habría operado inexorablemente la acción liberadora del tiempo, de forma tal que la acción penal habría prescrito.

Si el Fiscal Provincial formalizó denuncia por tal hecho y si el Juez Penal dictó auto de apertura de instrucción, Juan Pérez puede interponer una excepción de prescripción, la cual deberá declararse fundada y ordenándose el archivo definitivo de los actuados.

Por otro lado, la Prescripción Extraordinaria está referida al cumplimiento de un plazo adicional al plazo ordinario equivalente a una mitad de éste, ya que se han realizado actuaciones judiciales estando la acción penal expedita. Según se establece en el artículo 83 del Código Penal, este plazo extraordinario de prescripción se adiciona al ordinario.

Así, siguiendo el ejemplo anterior, si Juan Pérez fue procesado por el delito de usurpación en vía sumaria a mediados del 2003, pero debido a múltiples circunstancias hasta la fecha no fue sentenciado, siendo el plazo de prescripción ordinario igual a tres años y el plazo extraordinario, un año y medio, el plazo total de prescripción será igual a cuatro años y medio. Contabilizando el tiempo desde el 15 de julio del 2000, tenemos que en la actualidad el plazo transcurrido es superior a los cuatro años y medio, por lo cual, de oficio, a pedido del representante del Ministerio Público o a pedido de Parte deberá declararse fundada la excepción de Prescripción. La jurisprudencia en materia penal establece, en el expediente 6122-97 en un proceso de Omisión de Asistencia familiar, que este es un delito instantáneo de efectos permanentes, por lo que el plazo de Prescripción Extraordinaria para este tipo de delito es de cuatro años y medio, desde la fecha de la última notificación al procesado. 


\subsection{La excepción de Naturaleza de Acción}

La excepción de Naturaleza de Acción es una excepción que tiende a extinguir la acción penal cuando se alega que los hechos denunciados no constituyen delito o no son justiciables penalmente.

Puede ser considerada como el derecho de todo inculpado a solicitar que se archive definitivamente los actuados, porque considera que los hechos incriminados no tienen contenido penal. Así, por ejemplo, el caso de un sujeto al que se le denuncia y procesa por adulterio, hecho que no constituye delito, es decir, no se encuentra tipificado en las leyes penales. Un caso frecuente es la denuncia por estafa que hace un acreedor contra su deudor moroso, el juez que recibe la denuncia abre instrucción por este supuesto delito. La excepción será deducida para atacar la acción penal, exponiendo que el hecho es una deuda impaga y la vía que corresponde es la civil.

De igual manera, se procede cuando el hecho no es justiciablemente penalmente. Como sabemos, si bien existen hechos que se encuentran tipificados como delitos, estos no siempre son merecedores de sanción penal. Así, tenemos el caso de la excusa absolutoria para delitos contra el patrimonio: hurtos, apropiaciones, defraudaciones o daños que se causan los parientes consanguíneos en línea recta, los cónyuges, concubinos, y los hermanos y cuñados si viven juntos. En todos estos casos no se aplica la sanción penal.

El criterio del profesor San Martin Castro, citado en el libro La Excepción de Naturaleza de Acción, señala los siguientes supuestos:

- La conducta penalmente relevante sólo puede ser una conducta voluntaria (falta de acción).

-Si el delito es resultado, con el juicio de imputación objetiva.

-Si el delito es doloso, con la presencia de un tipo de error invencible o vencible.

-Si el delito es culposo, con la ausencia de infracción de la norma de cuidad y la previsibilidad del resultado o el caso fortuito.

-Si el delito es omisivo, con la ausencia de los requisitos que lo hacen exigible (situación típica, ausencia de una acción determinada y capacidad de realizar la acción, a la que se agregan los tipos de comisión por omisión la posición de garante, la producción de un resultado y la posibilidad de evitarlo). 
-Con los supuestos de atipicidad general, vinculados al cumplimiento de un deber de función o de profesión, al obrar por disposición de la ley, al acuerdo y a la insignificancia o conducta socialmente adecuada.

La jurisprudencia y la doctrina peruana son uniformes en considerar que, vía la excepción de Naturaleza de Acción, no se puede cuestionar la irresponsabilidad del imputado, por más que aparezcan elementos de prueba que acrediten la inocencia del imputado. El artículo 5to del Código de Procedimientos Penales establece que las excepciones pueden interponerse en cualquier estado.

La jurisprudencia nacional establece diversos criterios como, por ejemplo, en el expediente número 3128 -00, donde se señala que, habiéndose planteado la excepción de Naturaleza de Acción, basándose en cuestiones relativas al descargo de responsabilidad, estas deben ser tomadas como argumentos de defensa por lo que deben declararse infundada, puesto que el mayor o menor grado de responsabilidad debe verse en el proceso mismo.

\subsection{La excepción de Naturaleza de Juicio}

La excepción de Naturaleza de Juicio es una excepción cuya finalidad es la de regularizar el trámite procesal, en razón de que se ha dado a la denuncia interpuesta una sustentación distinta a la establecida por ley. La palabra sustentación tiene que entenderse como sinónimo de trámite y, de acuerdo a la magnitud de error, la regularización puede significar la anulación de determinadas diligencias que hayan resultado desnaturalizadas.

Como sabemos, en el proceso penal peruano existen dos vías: sumaria y ordinaria, por lo cual, de haberse iniciado proceso en una vía no correspondiente, el inculpado podrá deducir está excepción. Por esta excepción, se adecuan los actos procesales realizados en un proceso a la vía que corresponda, o se anulan dichos actos si es que no es posible la adecuación o no son propios de la vía correcta del caso. Así, por ejemplo, si se ventila en la vía ordinaria un caso de lesiones simples, la excepción deducida y declarada fundada ordenará regularizar el procedimiento, el cual debe continuar por la vía sumaria.

Este medio de defensa se da por cuanto el proceso penal debe desarrollarse dentro de un marco de legalidad y formalidad en el que la normatividad debe señalar cuál es la vía procedimental para cada uno de los procesos, sea ordinario, sumario u especial. En La Jurisprudencia Penal, Tomo III, página 193, se señala que la Excepción de Naturaleza de Juicio procede cuando a la denuncia se la ha dado un procedimiento que no corresponde y si es que faltare un requisito de procedibilidad, lo que cabe es la Cuestión Previa. 


\subsection{La excepción de Amnistía}

La excepción de Amnistía es una excepción que se deduce con el fin de extinguir la acción penal en virtud de haberse concedido la amnistía respecto a un hecho delictuoso. La Amnistía, conforme lo señala de la Cruz Espejo, es un acto de poder soberano que cubre con el velo del olvido las infracciones penales de cierta clase, dando por concluidos los procesos comenzados, declarando que no deben iniciarse los pendientes o bien declarando automáticamente cumplidas las condenas pronunciadas o en vías de cumplimiento.

La Amnistía es una manifestación del derecho de gracia dirigida a "olvidar" la comisión de delitos de índole político-social. Se constituye en una facultad del Poder Legislativo mediante la cual se ampara con la impunidad a todos aquellos que están denunciados, procesados o condenados por haber cometido delitos político-sociales. En tal sentido, se emite una Ley de Amnistía de carácter general por la cual se ordena archivar todos los procesos por los hechos a que hace referencia la norma legal.

La Amnistía está destinada a eliminar la punibilidad de los delitos políticos perpetrados. Es una medida de carácter objetivo y de alcance general: se otorga en consideración al delito cometido y no en función de los individuos, y comprende a todas las personas involucradas en dichos ilícitos. Para que surta efecto, luego de promulgarse la ley, el interesado tiene que deducir la excepción de Amnistía y tiene que emitirse una resolución dentro del proceso ordenando el archivamiento definitivo. El Indulto, por el contrario, es personal, y es una facultad del Poder Ejecutivo, específicamente del Presidente de la República, de perdonar la ejecución de la pena.

De abrirse investigación por los mismos hechos materia de la Amnistía, el inculpado o condenado tiene el derecho de deducir esta excepción. El derecho de Amnistía es una potestad exclusiva del Congreso de la República, por lo que se la debe asumir como una medida legislativa.

Para finalizar, podemos sostener que los Medios Técnicos de Defensa constituyen formas de oponerse al ejercicio de la acción penal incoada y, en muchos casos, facilitan la labor de los órganos jurisdiccionales a fin de concluir un proceso que resulta un gasto inmenso para el Estado. En la actualidad, de acuerdo al Código de Procedimientos Penales, en sus artículos $4^{\circ}$ y $5^{\circ}$ se establecen la Cuestión Previa, la Cuestión Pre Judicial, y las Excepciones como las de Naturaleza de Acción, la Cosa Juzgada, la Prescripción. En este sentido, la jurisprudencia y la doctrina en materia penal han avanzado bastante en este tema. 


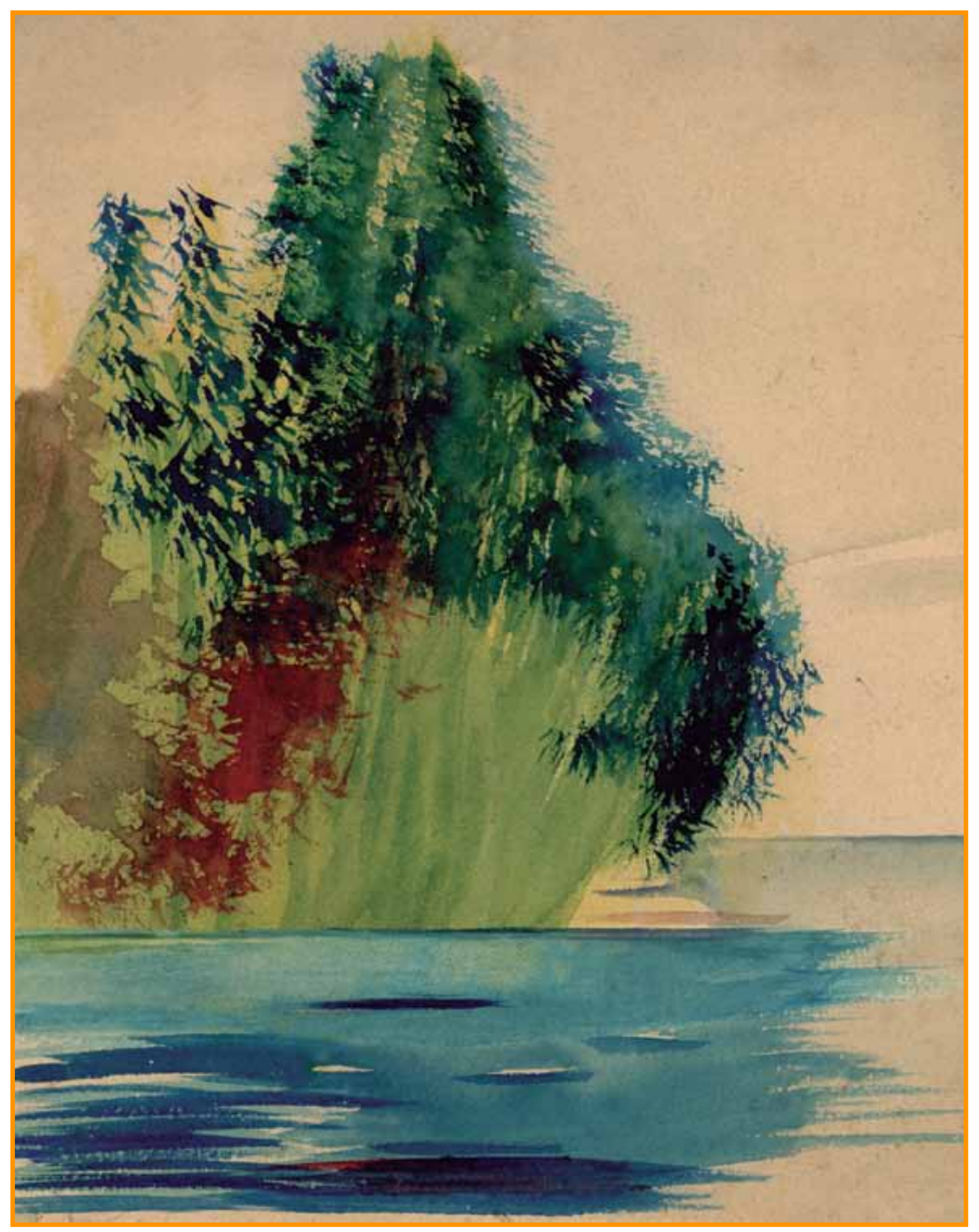

